\title{
Preparation of Fac-Tris(2-Phenylpyridinato) Iridium(III)
}

\author{
Kip A. Teegardin and Jimmie D. Weaver \\ Department of Chemistry, Oklahoma State University, Stillwater, OK 74078
}

\section{Graphical Abstract}

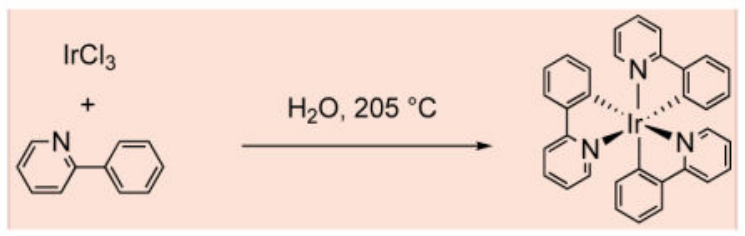

\section{Procedure (Note 1) \\ Fac-tris(2-phenylpyridinato) iridium(III) (A)}

Iridium (III) chloride anhydrous ( $0.65 \mathrm{~g}, 2.18 \mathrm{mmol}, 1$ equiv) (Note 2), 2-phenylpyridine (3.74 $\mathrm{mL}, 26.1 \mathrm{mmol}, 12.0$ equiv) (Note 3$)$, and $0.65 \mathrm{~L}$ of DI water ( $0.003 \mathrm{M}$ with respect to $\mathrm{IrCl}_{3}$ ) is added to a $1 \mathrm{~L}$ Parr reactor (Figure 1) (Notes 4, 5, and 6). The reaction mixture is pressurized with argon (10.0 psi), stirred and then depressurized three times, and finally

\footnotetext{
Checked by Hao Wu, Alexander Sienkiewicz, and Chris Senanayake

${ }^{1}$ Prior to performing each reaction, a thorough hazard analysis and risk assessment should be carried out with regard to each chemical substance and experimental operation on the scale planned and in the context of the laboratory where the procedures will be carried out. Guidelines for carrying out risk assessments and for analyzing the hazards associated with chemicals can be found in references such as Chapter 4 of "Prudent Practices in the Laboratory" (The National Academies Press, Washington, D.C., 2011; the full text can be accessed free of charge at https://www.nap.edu/catalog/12654/prudent-practices-in-the-laboratory-handling-and-management-ofchemical). See also "Identifying and Evaluating Hazards in Research Laboratories" (American Chemical Society, 2015) which is available via the associated website "Hazard Assessment in Research Laboratories" at https://www.acs.org/content/acs/en/about/ governance/committees/chemicalsafety/hazard-assessment.html. In the case of this procedure, the risk assessment should include (but not necessarily be limited to) an evaluation of the potential hazards associated with iridium (III) chloride anhydrous, 2-phenylpyridine, argon, dichloromethane, Celite ${ }^{\circledR}$, hydrochloric acid solution, and hexanes, as well as the proper procedures for operating a Paar apparatus. This reaction is run well above the boiling point of water and reaches high pressures. The reaction should be cooled to room temperature before venting and opening. Only reactors designed to handle this pressure should be used and shields used as appropriate.

${ }_{3}^{2} \mathrm{IrCl}_{3}$ was obtained from Beantown Chemicals (BTC), available through VWR.

3 2-Phenylpyridine was obtained from AK scientific and used as received.

${ }_{4}$ A 2 L Parr stirred reactor was fitted with an inlet and outlet valve, a Duro United pressure gauge (0-5000 psi), and a $526 \mathrm{HCPH}$ rupture disc was used for the reaction (Figure 1a). In series with a 4843 controller the reactor was heated with a Parr heater assembly (model no. A1445HC3EE) controlled by a type J thermocouple (15.5 in. length) (Figure 1b). We have found that the stirring and glass sleeve options are unnecessary for the success of the reaction. The Checkers used a 1 L Parr series 4520 stirred reactor, material of construction 316L, Maximum Allowable Working Pressure $1900 \mathrm{psi}$ at $350^{\circ} \mathrm{C}$. A Pressure relief valve was installed, Parr\# A140VB2PC and set to 600 psi for safety. In addition we installed a Swagelok Pressure transducer, model\# PTI-S-NG1500-11AQ with a frange of $0-1500 \mathrm{psi}$ so that we could log the internal pressure. A second JKem model J thermocouple $1 / 16 \times 12$ inches was installed for logging the internal temperature during the reaction. The heating and cooling was controlled with a Parr model 4843 controller along with a magnetic solenoid valve on the cold water loop. We also discovered that the headspace in the reactor was very important to maintaining operable pressures. A headspace of $25 \%$ is needed. We found if the headspace in the same $2 \mathrm{~L} \mathrm{Parr} \mathrm{reactor}$ was decreased to $12.5 \%$ (1.75 L water), the reactor leaked and displayed significant pressure. Again, further safety precautions must be taken when changing the headspace to water ratio. With a lower fill in the reactor the system is operating as saturated steam, gas phase and liquid phase in an equilibrium, so the pressure should be pretty constant. However as the amount of water is increased, and it expands upon heating there is no longer head space for steam to form. Once there is no room for steam, there is no equilibrium, and you are in a situation where hydraulic pressure from the water is pushing your reactor apart.
} 
charged again with argon before sealing (Note 7). The reaction mixture is heated to $205^{\circ} \mathrm{C}$ for $48 \mathrm{~h}$. Then the reactor is cooled to $20^{\circ} \mathrm{C}$ with internal cooling coils. At the end of the experiment the reactor was left in the stand and the contents cooled to $20{ }^{\circ} \mathrm{C}$ using cold water. After cooling, the reactor is opened revealing an insoluble yellow solid on the surfaces (Figure 2) and dispersed in the aqueous phase (Note 8). All contents are transferred slowly to a $6 \mathrm{~L}$ separatory funnel aided by a large $5 \mathrm{~cm}$ glass funnel. Then the interior of the reactor is mechanically scraped (to extract the yellow material), with metal tongs, cotton balls (25 in total), and $500 \mathrm{~mL}$ of dichloromethane (DCM) from a spray bottle, and again all contents are added to the separatory funnel (Notes 9 and 10).

While still in the funnel, the cotton is rinsed with $25 \mathrm{~mL}$ of DCM from a spray bottle and evenly pressed with tongs to release the yellow material from the cotton (Note 9). After removing the cotton, the solution is then diluted with $2.5 \mathrm{~L}$ of DCM. The separatory funnel is shaken vigorously, allowed to settle and again shaken, and the organic layer is then slowly separated from the aqueous layer (Notes 11, 12 and 13) and the aqueous layer is further extracted with more DCM $(3 \times 10 \mathrm{~mL})$, and the organic layers are combined (Note 14). The aqueous layers are kept for future ligand recovery. The combined organic layer is washed

\footnotetext{
${ }^{5}$ Inspecting the equipment, and maintaining it prior to starting, in addition to doing a pressure test before starting should eliminate most equipment failure. Having equipment failure with water at $200^{\circ} \mathrm{C}$ can be hazardous. The experiment was carried out in a closed hood for safety. In the pressure test, the reactor was charged with $0.65 \mathrm{~L}$ water only. The internal temperature and pressure were monitored using the Parr controller. The temperature and pressure were found very constant over $48 \mathrm{~h}$. The primary cause for incomplete or failed reactions stems from equipment failure. Since the reaction is highly dependent on temperature it is important to insure probes and controllers are working properly, and leak checks are performed on the entire system before every reaction. Insure all valves are free of obstruction and all areas are clean. It is imperative that the reactor temperature stays above $200{ }^{\circ} \mathrm{C}$. The reactor used in the above reactions had shown significant temperature deviation $+/-5^{\circ} \mathrm{C}$. So we set our controller to $205^{\circ} \mathrm{C}$ to insure the reactor stays above $200{ }^{\circ} \mathrm{C}$.

${ }^{6}$ See the attached plot (generated by the Checkers) for expansion of pure water One must be careful to ensure that there is room for steam to form or else it is possible to have a catastrophic failure.
}

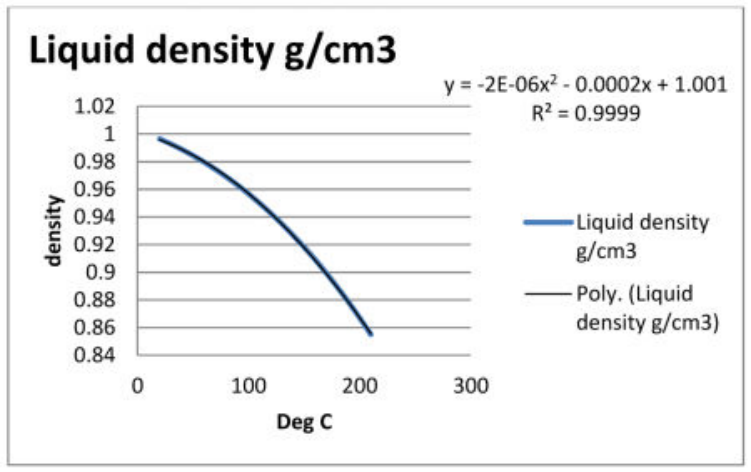

${ }^{7}$ If the Parr reactor is not equipped with a stirring mechanism, after pressurizing the reactor with argon one can gently rock the reactor back and forth to mix the contents

${ }^{8}$ Suspended dull yellow colored water mixtures is indicative of an unsuccessful reaction, while insoluble yellow colored (Figure 2) water mixtures are indicative of a successful reaction. For the $\operatorname{Ir}(\mathrm{ppy}) 3$ catalyst, the primary contaminant after the workup is the chloro-bridging dimer which is a dull yellow color intermediate en-route to the desired product. This was determined by NMR analysis reaction mixtures after work up ${ }^{2}$.

${ }^{9}$ Yellow solid around the walls, probe shafts, and stirring impellers should be examined for yellow residue and any residue should be scraped or extracted with DCM/cotton to insure high yields (Figure 3). The cotton was placed directly into the separatory funnel only to cut process time. Alternatively, the cotton can be placed into a beaker and then the cotton material can be extracted with DCM, then the DCM extracts can be added to the separatory funnel.

${ }^{10}$ There may be yellow solid that did not dissolve completely into the DCM. This is normal; as the $1 \mathrm{M} \mathrm{HCl}$ washes are performed and ligand is removed the catalyst will eventually partition fully into the organic layer.

${ }^{11}$ It is important drain to the organic layer slowly to avoid disrupting the phase separation. In this large scale work up the aqueous layer tends to swirl into the organic layer as the organic is dispersed through the separatory funnel, if separation is done quickly. It is important to insure that the separation of the organic layer from the aqueous layer is performed slowly in all phase separations. 
with a $1 \mathrm{M} \mathrm{HCl}$ solution, with vigorous mixing prior to separation $(3 \times 900 \mathrm{~mL})$. Each $\mathrm{HCl}$ wash is then back extracted with DCM $(3 \times 10 \mathrm{~mL})$ to insure complete recovery of the product. After the final wash, the organic layer is filtered slowly $(20 \mathrm{~min})$ through a Celite ${ }^{\circledR}$ $(35 \mathrm{~g})$ pad on top of a $150 \mathrm{~mL}$ medium porosity sintered glass funnel, into a $3 \mathrm{~L}$ roundbottomed flask, and then dried with $30 \mathrm{~g}$ of $\mathrm{MgSO}_{4}$. After filtering the drying reagent using a $4 \mathrm{~L}$ Erlenmyer flask fitted with a $5 \mathrm{~cm}$ funnel/cotton plug, a homogenous aliquot is removed for NMR analysis (Note 15). Finally, the solvent is removed in batches by transferring to a $2.5 \mathrm{~L}$ round-bottomed flask by rotary evaporation $\left(35^{\circ} \mathrm{C}, 30 \mathrm{~mm} \mathrm{Hg}, 150\right.$ rpm) to afford $1.35 \mathrm{~g}(94 \%)$ of $\operatorname{Ir}(\mathrm{ppy})_{3}$ as a bright yellow solid (Note 16).

Further purification of $\operatorname{Ir}(\mathrm{ppy})_{3}$ can be performed by adding the yellow solid to a $1 \mathrm{~L}$ roundbottomed flask and adding $600 \mathrm{~mL}$ of distilled hexanes. The solid material is then sonicated until a uniform slurry is achieved, and $5 \mathrm{~mL}$ of dichloromethane is added (Note 17). The liquid is swirled giving a slight yellow tint to the solution indicating successful dissolution of a colored compound, and selective extraction of the impurities. Then the slurry is slowly poured through a $50 \mathrm{~mL}$ fine porosity sintered glass funnel to collect the yellow solid, and the filtrate is collected into a $1 \mathrm{~L}$ Erlenmeyer flask. The yellow solid is air dried on the filter to afford $1.29 \mathrm{~g}(91 \%)$ (Notes 18 and 19) of the product in >97\% purity (Notes 20 and 21).

\footnotetext{
${ }^{12}$ There tends to be a small emulsion layer in between the organic and aqueous layers during the work up which contains some black material. Care should be taken to avoid the inclusion of this emulsion layer. The extra DCM rinses serve to fully extract the product that remains in the emulsion and on the walls of the separatory funnel.

${ }^{13}$ Because it builds up pressure, it is important to vent the separatory funnel to avoid loss of product and to avoid injury. Some loss of product is apparent when venting the large $6 \mathrm{~L}$ separatory funnel through the stopcock, while not the standard technique, venting was performed by securing the separatory funnel back to the ring stand and carefully removing the stopper.

${ }^{14}$ Thin-layer chromatography (TLC) was used to insure all ligand was extracted from the organic layer. TLC was performed using Sorbent Technologies Silica Gel XHL normal phase plates and utilizing an eluent system of hexanes/EtOAc (9:1). Rf values are measured using thin layer chromatography (TLC), (obtained from sorbent technology Silica XHL TLC Plates, w/UV254, glass backed, $250 \mu \mathrm{m}, 20 \times 20 \mathrm{~cm}$ ) see Table 1 .

${ }^{15}$ The solubility of the catalysts is relatively low in dichloromethane (thus a large volume of solvent was used to dilute the compound), yet the impurities (the chloro-bridging dimer and the excess ligand) are significantly more soluble. Removing an aliquot while the entire mixture is homogenous will insure an accurate NMR analysis.

${ }^{16}$ Since the solubility of the catalyst is low in most volatile solvents transferring the material to a smaller container can be laborious and require copious amounts of solvent. It is recommended to scrape the sides of the round bottom meticulously and transfer all the material possible as a solid. Then any remaining solid material can be dissolved with solvent and transferred to the smaller container, thus, minimizing the solvent use.

${ }^{17}$ To insure high yields of product, the purification step must be performed with care. The amount of DCM that is added to the hexanes can vary depending on the purity of the sample. Lower amounts of DCM are added for purer samples and larger amounts are used for compounds of lower purity. The ratio for the purification technique is typically 1/120 (DCM/hexanes).

${ }^{18}$ Characterization of fac-tris(2-phenylpyridinato) iridium(III) ${ }^{1} \mathrm{H}$ NMR $\left(500 \mathrm{MHz}, \mathrm{CD}_{2} \mathrm{Cl}_{2}\right)\left(5.32 \mathrm{ppm}\right.$ for $\mathrm{CH}_{2} \mathrm{Cl}_{2}$ in $\left.\mathrm{CD}_{2} \mathrm{Cl}_{2}\right) \delta$ : $6.78(\mathrm{dt}, J=16.1,7.4 \mathrm{~Hz}, 6 \mathrm{H}), 6.90(\mathrm{dt}, J=18.9,6.4 \mathrm{~Hz}, 6 \mathrm{H}), 7.57(\mathrm{~d}, J=5.3 \mathrm{~Hz}, 3 \mathrm{H}), 7.64-7.68(\mathrm{~m}, 6 \mathrm{H}), 7.92(\mathrm{~d}, J=8.2 \mathrm{~Hz}, 3 \mathrm{H})$. ${ }^{13} \mathrm{C}$ NMR (400 MHz, C6 6 6 with NMP) $\delta: 119.1,120.3,122.2,124.6,130.1,136.5,137.7,144.4,147.3,161.9,167.1$. IR (film): $3034,2923,1599,1580,1560,1470,1413,1261,1159,752,732 \mathrm{~cm}^{-1}$.

${ }^{19} \mathrm{~A}$ second reaction on the same scale provided $1.30 \mathrm{~g}(91 \%)$ of the product in $>98 \%$ purity.

${ }^{20}$ The weight percent was determined by quantitative NMR using trimethoxybenzene as the internal standard. The solubility of Irppy 3 in most deuterated solvents is low, which makes weighing out the necessarily small amounts of dissolvable compound challenging. It is best to accurately weigh out a larger sample (>100 $\mathrm{mg}$ of the standard or compound) and dissolve the compound into protiodichloromethane using a volumetric flask to give an accurate molar solution. Then appropriate volumes of the standard and compound solutions can be mixed. Next, the protio-solvent removed and the mixture redissolved in the appropriate deuterated solvent. A proton NMR spectrum is thus obtained for the mixture with a minimum relaxation delay of $30 \mathrm{~s}$.

${ }^{21}$ If using more expensive ligands it may be economical to recover the valuable ligand. Below is an example of the 2-phenylpyridine ligand recovery, which was not confirmed by the checkers: The previously retained acidic aqueous layers from a $4.46 \mathrm{mmol}$ reaction are added to a 4 L Erlenmeyer flask with a $60 \mathrm{~mm}$ PTFE octagon stir bar. The solution is stirred and slowly brought to $\mathrm{pH} 10 \mathrm{by}$ adding $119 \mathrm{~g}$ of $\mathrm{NaOH}$ pellets in 10 portions (Note 22). The solution is added to a $6 \mathrm{~L}$ separatory funnel and the ligand is extracted from the salty water with DCM $(6 \times 1.2 \mathrm{~L})$. The combined organic extracts are added to a $20 \mathrm{~L}$ metal canister and are dried with $20 \mathrm{~g}$ of $\mathrm{MgSO}_{4}$. After filtering the drying reagent through a $5 \mathrm{~cm}$ funnel with a cotton plug into another $20 \mathrm{~L}$ canister the solvent is removed in batches by utilizing a continuous rotary evaporation setup $\left(35^{\circ} \mathrm{C}, 130 \mathrm{~mm} \mathrm{Hg}, 100 \mathrm{rpm}\right.$ ) (Figure 4) to afford 5.90 g 96.4$97.0 \%$ (based on excess 9 equiv) of 2-phenylpyridine is recovered in $97.7-98.5 \%$ purity compared to a standard signal (trimethoxybenzene).
} 


\section{Working with Hazardous Chemicals}

The procedures in Organic Syntheses are intended for use only by persons with proper training in experimental organic chemistry. All hazardous materials should be handled using the standard procedures for work with chemicals described in references such as "Prudent Practices in the Laboratory" (The National Academies Press, Washington, D.C., 2011; the full text can be accessed free of charge at http://www.nap.edu/catalog.php? record_id=12654). All chemical waste should be disposed of in accordance with local regulations. For general guidelines for the management of chemical waste, see Chapter 8 of Prudent Practices.

In some articles in Organic Syntheses, chemical-specific hazards are highlighted in red "Caution Notes" within a procedure. It is important to recognize that the absence of a caution note does not imply that no significant hazards are associated with the chemicals involved in that procedure. Prior to performing a reaction, a thorough risk assessment should be carried out that includes a review of the potential hazards associated with each chemical and experimental operation on the scale that is planned for the procedure. Guidelines for carrying out a risk assessment and for analyzing the hazards associated with chemicals can be found in Chapter 4 of Prudent Practices.

The procedures described in Organic Syntheses are provided as published and are conducted at one's own risk. Organic Syntheses, Inc., its Editors, and its Board of Directors do not warrant or guarantee the safety of individuals using these procedures and hereby disclaim any liability for any injuries or damages claimed to have resulted from or related in any way to the procedures herein.

\section{Discussion}

For more than 30 years, transition metal complexes have been known to mediate singleelectron transfers (SET) and have led to SET-initiated polymerization reactions, ${ }^{3}$ dyesensitized solar cells, ${ }^{4}$ and light emitting diodes. ${ }^{5}$ While the use of these complexes in synthesis dates back to the 1980 's, application towards synthetic organic chemistry was sporadic. ${ }^{6}$ Early reports of transition metal-based photocatalytic mediated organic transformations utilized Ru-based photocatalysts such as tris-(2,2' -bipyridine) ruthenium(II) $\left(\mathrm{Ru}(\mathrm{bpy}) 3^{2+}\right)$, which when excited by visible light undergoes a metal to ligand charge transfer (MLCT) and facilitates one-electron oxidation or reduction of the complex. ${ }^{7}$ In 1985, King and coworkers reported the synthesis and characterization of the neutral fac-trisphenylpyridinato iridium (III), (Ir(ppy) ${ }_{3}$ ) photocatalyst. $^{8}$ In general, the neutral Irphotocatalysts tend to have a longer lived excited-state lifetime and to be substantially more reducing when compared to ruthenium based photocatalysts, and thus are a complimentary class of photocatalysts.

During the last decade photocatalysis has grown in importance to the synthetic community, and the neutral tris-homoleptic Ir-complexes are a vital class of photocatalyst. ${ }^{9}$ In 2012 , Stephenson ${ }^{10}$ reported an efficient hydrodeiodination of alkyl, alkenyl, and aryl iodides using $\operatorname{Ir}(\text { ppy })_{3}$. In 2014, Macmillian ${ }^{11}$ investigated several neutral complexes $\operatorname{Ir}(p \text {-F-ppy })_{3}$, 
$\operatorname{Ir}(\mathrm{dFppy})_{3}, \operatorname{Ir}[p-\mathrm{F}(t-\mathrm{Bu})-\mathrm{ppy}]_{3}$, and $\operatorname{Ir}[\mathrm{dF}(t-\mathrm{Bu})-\mathrm{ppy}]_{3}$ which all out performed $\operatorname{Ir}(\mathrm{ppy})_{3}$ in the decarboxylative arylation of alpha amino acids. Recently other groups, ${ }^{9}$ including our own, ${ }^{12}$ have utilized the fac-tris-homoleptic iridium (III) complexes. In addition to redox chemistry, Ir-based photocatalyts can also undergo quenching through an energy transfer process with styrenyl derivatives which leads to the contra-thermodynamic isomerization to the less conjugated alkene. ${ }^{12 b}, 13,13 b, 14,15,16$ We have shown that while the emissive energy of the photocatalyst is an important feature in controlling this process, that unlike other sensitizers the substituents play a decisive role in determining which process will dominate. 13a Thus, there is a need to be able to efficiently access these complexes, and others, so that a full understanding of the structure/function relationship is possible, which will elevate our collective synthetic capabilities.

Despite the rapidly increasing utility of the homoleptic iridium (III) complexes in organic syntheses, there is a significant lack of commercial availability ${ }^{16}$ which likely stems from lack of a general synthetic method that can produce these complexes in a cost efficient manner. There are a number of reported synthetic methods that use the more expensive $\operatorname{Ir}(\mathrm{acac})_{3}{ }^{11-12,17}\left(\$ 73970 / \mathrm{mol} \operatorname{Ir}(\mathrm{acac})_{3}\right.$ vs $\left.\$ 18,750 / \mathrm{mol} \mathrm{IrCl}_{3}\right)$, or alternatively require two synthetic steps. The first step results in the formation of a chloro-bridging dimer via coordination of two phenylpyridine ligands. Then, in a subsequent synthetic step the halogen is abstracted, often aided by silver, and a third phenylpyridine is added via cyclometalation.

${ }^{18}$ Even in the case of the tris-homoleptic cyclometalated complexes, this two-step sequence is commonly employed. Ideally, one could place all three bidentate ligands in the same reaction to generate the thermodynamically favored facial-homoleptic iridium (III) complex. It has been known that the meridional-homoleptic iridium (III) complex is the kinetically favored product but the facial complex, obtained at temperatures greater than $200{ }^{\circ} \mathrm{C}$, is the thermodynamically favored product. ${ }^{18 \mathrm{~b}}$ Konno ${ }^{19}$ reported microwave synthesis of triscyclometalated iridium complexes, but this required a large excess of ligand (50 to 100 equiv) which limits the scope of the reaction to readily available ligands. Perhaps more importantly, the scale of the reaction is limited by the microwave equipment used. Therefore, in 2014 we developed and published a simple, reliable, and straightforward prep that would allow us to acquire the facial-homoleptic iridium complexes in high yields via a selective one step process starting with the least expensive source of $\mathrm{Ir}(\mathrm{III})$ salt, $\mathrm{IrCl}_{3}$. Ideally, water was the reaction solvent (figure 5). ${ }^{20}$

While we and others have used this method to make gram scale quantities of these complexes, there are some notable shortcomings. Namely, purification of the complexes via column chromatography was time intensive, and required copious amounts of organic solvents, and was particularly challenging because of the low solubility of these complexes. Often the isolation of the complex was more challenging than its synthesis. Since this publication, we have worked to improve the method, in particular we have focused on making the reaction more scalable. The three main objectives were to maintain high purity of complex on a gram scale, eliminate chromatography, and recover the excess ligand. Herein, we report a modified method which has been applied to Irppy 3 to obtain multigram quantities of the photocatalyst (up to $2.85 \mathrm{~g}$ ) in high purity (>97\%), without the use of a column, and with excellent recovery of excess ligand in good yield (up to $97.0 \%$ ). While not 
checked, we also obtained similar results by applying this method to $\operatorname{Ir}(\mathrm{diFppy})_{3} \mathbf{1 d}$ where the reaction yielded $1.82 \mathrm{~g}$ of catalyst (71.4\% yield) with high purity (>97\%) indicating that the method works with more elaborate ligands that are less accessible. Additionally, while we did not demonstrate the recovery of the organic solvent, it is conceivable that the DCM could also be recovered in high purity. We believe this method to be quite general to this family of photocatalysts. Consequently, this method will facilitate exploration of the chemistry of these Ir-complexes, as well as enable applications which may require more substantial quantities of Ir-photocatalysts.

\section{Biographies}

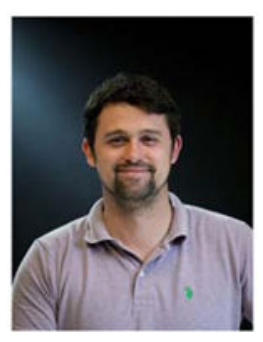

Kip Teegardin obtained his B.Sc. in Chemistry with a concentration in Biochemistry, from the University of Arkansas-Fort Smith, in 2012 after his military service with the 82 ${ }^{\text {nd }}$ Airborne Division (U.S. Army) in 2008. He is currently working on his Ph.D in the Weaver group at Oklahoma State University where his research currently focuses on the polyfluoroarylation of oxazolones leading to non-natural fluorinated amino acids and their derivatives.

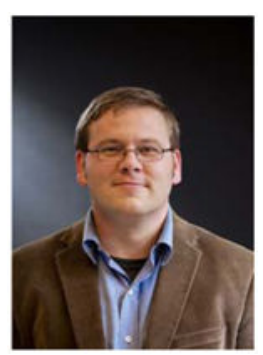

Jimmie Weaver obtained a B.S. in Chemistry with math and physics minors from Southern Nazarene University (2004), a PhD (2010) from the University of Kansas where he worked with Prof. Jon Tunge, and then completed a post-doc position with Jon Ellman (Yale). In the fall of 2012, Jimmie took a position at Oklahoma State University where he has established an independent research program focused on the catalytic generation and exploitation of reactive intermediates for really cool applications such as $\mathrm{C}-\mathrm{H}$ and $\mathrm{C}-\mathrm{F}$ functionalization, cross-coupling of minimally activated partners, uphill catalysis, and developing forms of energetic currency. 


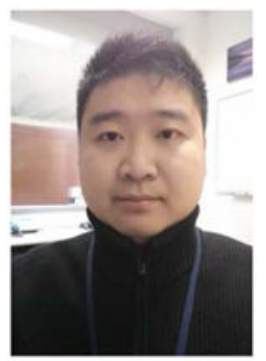

Hao Wu obtained his B.S. in Chemistry from Peking University in 2009, where he studied conjugate macrocycles and oligomers under the mentorship of Prof. Dahui Zhao. He completed his Ph.D. degree in organic chemistry from Boston College in 2015 under the supervision of Prof. Amir H. Hoveyda, working on catalytic enantioselective processes of CB, C-C and C-Si bond formations. He is currently a senior scientist in Boehringer Ingelheim Pharm. Inc. since 2015. His research interest is the development of reliable and robust catalysis for process chemistry.

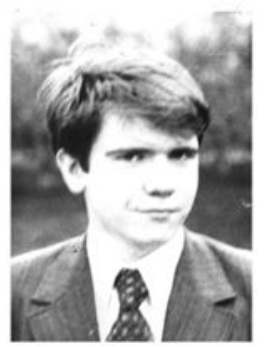

Alexander Sienkiewicz obtained his M.S. in Chemistry from Kiev State University in 1977, where he studied complexes of phosphoryl ligands with metal halides under the mentorship of Prof. Victor Skopenko. He completed his Ph.D. degree in Coordination Chemistry from the same University in 1987 under the supervision of Prof. Victor Skopenko, working on synthesis and characterization of new polynuclear cage complexes containing chelating amino alcohols, amines, and amino acids and transition metals. Currently he is a senior scientist in Boehringer Ingelheim Pharm. Inc. since 2015. He participates in the development of reliable catalytic techniques for process chemistry.

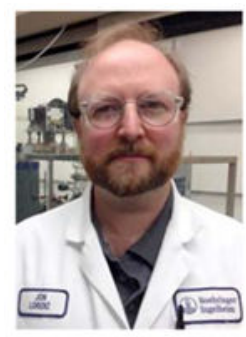

Jon C. Lorenz received a B.A. degree in Chemistry from Whitman College, Walla Walla, WA in 1995. He then joined the United States Peace Corps and taught science in the North West Province of Cameroon. Upon returning to the United States he began his graduate studies at Colorado State University, where he received a Ph.D. in organic chemistry under 
the guidance of Professor Yian Shi in 2002. Subsequently, he joined the Department of Chemical Development at Boehringer Ingelheim Pharmaceuticals in Ridgefield, CT. In 2009 Jon moved to the Scale-up support group and then the kilo lab in Ridgefield, where he is currently a Senior Research Fellow. His research interests include the development and application of catalytic asymmetric reactions, use of Process Analytic Technology in Scaleup, continuous processing for scale-up, and the many facets of process development.

\section{References}

1. 107 Physical Science, Oklahoma State University, Stillwater, OK 74078. Jimmie.Weaver@okstate.edu, We thank NIGMS (RO1 GM115697) for financial support of this research.

2. Scarpelli F, Ionescu A, Ricciardi L, Plastina P, Aiello I, La Deda M, Crispini A, Ghedini M, Godbert N. Dalton Trans. 2016; 45:17264-17273. [PubMed: 27722340]

3. Lalevee J, Peter M, Dumur F, Gigmes D, Blanchard N, Tehfe M-A, Morlet-Savary F, Fouassier JP. Chem Eur J. 2011; 17:15027-15031. [PubMed: 22124944]

4. Kalyanasundaram K, Grätzel M. Coord Chem Rev. 1998; 177:347-414.

5. Lowry MS, Bernhard S. Chem Eur J. 2006; 12:7970-7977. [PubMed: 16933348]

6. (a) Pac C, Ihama M, Yasuda M, Miyauchi Y, Sakurai H. J Am Chem Soc. 1981; 103:6495-6497.(b) Cano-Yelo H, Deronzier A. J Chem Soc, Perkin Trans. 1984; 2:1093-1098.(c) Narayanam JMR, Stephenson CRJ. Chem Soc Rev. 2011; 40:102-113. [PubMed: 20532341]

7. McCusker JK. Acc Chem Res. 2003; 36:876-887. [PubMed: 14674779]

8. King KA, Spellane PJ, Watts RJ. J Am Chem Soc. 1985; 107:1431-1432.

9. Prier CK, Rankic DA, MacMillan DWC. Chem Rev. 2013; 113:5322-5363. [PubMed: 23509883]

10. Nguyen JD, D’Amato EM, Narayanam JMR, Stephenson CRJ. Nat Chem. 2012; 4:854-859. [PubMed: 23001000]

11. Zuo Z, MacMillan DWC. J Am Chem Soc. 2014; 136:5257-5260. [PubMed: 24712922]

12. (a) Singh A, Arora A, Weaver JD. Org Lett. 2013; 15:5390-5393. [PubMed: 24098895] (b) Singh K, Staig SJ, Weaver JD. J Am Chem Soc. 2014; 136:5275-5278. [PubMed: 24678625] (c) Senaweera SM, Singh A, Weaver JD. J Am Chem Soc. 2014; 136:3002-3005. [PubMed: 24547940] (d) Singh A, Kubik JJ, Weaver JD. Chem Sci. 2015; 6:7206-7212. [PubMed: 29861956]

13. (a) Singh A, Fennell CJ, Weaver JD. Chem Sci. 2016; 7:6796-6802. [PubMed: 28042465] (b) Fabry DC, Ronge MA, Rueping M. Chem - Eur J. 2015; 21:5350-5354. [PubMed: 25694030]

14. Rackl D, Kreitmeier P, Reiser O. Green Chem. 2016; 18:214-219.

15. Lu Z, Yoon TP. Angew Chem Int Ed. 2012; 51:10329-10332.

16. Teegardin K, Day JI, Chank J, Weaver J. Org Process Res Dev. 2016; 20:1156-1163. [PubMed: 27499607]

17. (a) Arora A, Teegardin KA, Weaver JD. Org Lett. 2015; 17:3722-3725. [PubMed: 26172544] (b) Chu L, Ohta C, Zuo Z, MacMillan DWC. J Am Chem Soc. 2014; 136:10886-10889. [PubMed: 25032785] (c) Weaver J, Senaweera S. Tetrahedron. 2014; 70:7413-7428.(d) Devery JJ III, Douglas JJ, Nguyen JD, Cole KP, Flowers RA II, Stephenson CRJ. Chem Sci. 2015; 6:537-541. [PubMed: 28706624] (e) Terrett JA, Clift MD, MacMillan DWC. J Am Chem Soc. 2014; 136:6858-6861. [PubMed: 24754456] (f) Dedeian K, Djurovich PI, Garces FO, Carlson G, Watts RJ. Inorg Chem. 1991; 30:1685-1687.(g) Singh A, Arora A, Weaver JD. Org Lett. 2013; 15:53905393. [PubMed: 24098895] (h) Wallentin CJ, Nguyen JD, Finkbeiner P, Stephenson CRJ. J Am Chem Soc. 2012; 134:8875-8884. [PubMed: 22486313]

18. (a) McDonald AR, Lutz M, von Chrzanowski LS, van Klink GPM, Spek AL, van Koten G. Inorg Chem. 2008; 47:6681-6691. [PubMed: 18588287] (b) Tamayo AB, Alleyne BD, Djurovich PI, Lamansky S, Tsyba I, Ho NN, Bau R, Thompson ME. J Am Chem Soc. 2003; 125:7377-7387. [PubMed: 12797812]

19. Konno H, Sasaki Y. Chem Lett. 2003; 32:252-253. 
20. Singh A, Teegardin K, Kelly M, Prasad KS, Krishnan S, Weaver JD. J Organomet Chem. 2015; 776:51-59.

\section{Appendix. Chemical Abstracts Nomenclature (Registry Number)}

$\mathrm{IrCl}_{3}$ : Iridium trichloride; (10025-83-9)

2-Phenylpyridine: pyridine, 2-phenyl-; (1008-89-5)

Dichloromethane (DCM): methane, dichloro-; (75-09-2)

Hydrochloric acid (HCl): hydrochloric acid; (7647-01-0)

Ceolite: diatomaceous earth; (68855-54-9)

$\mathrm{MgSO}_{4}$ : magnesium sulfate (7487-88-9)

Hexanes: hexanes: (110-54-3)

$\mathrm{NaOH}$ : sodium hydroxide: (1310-73-2) 


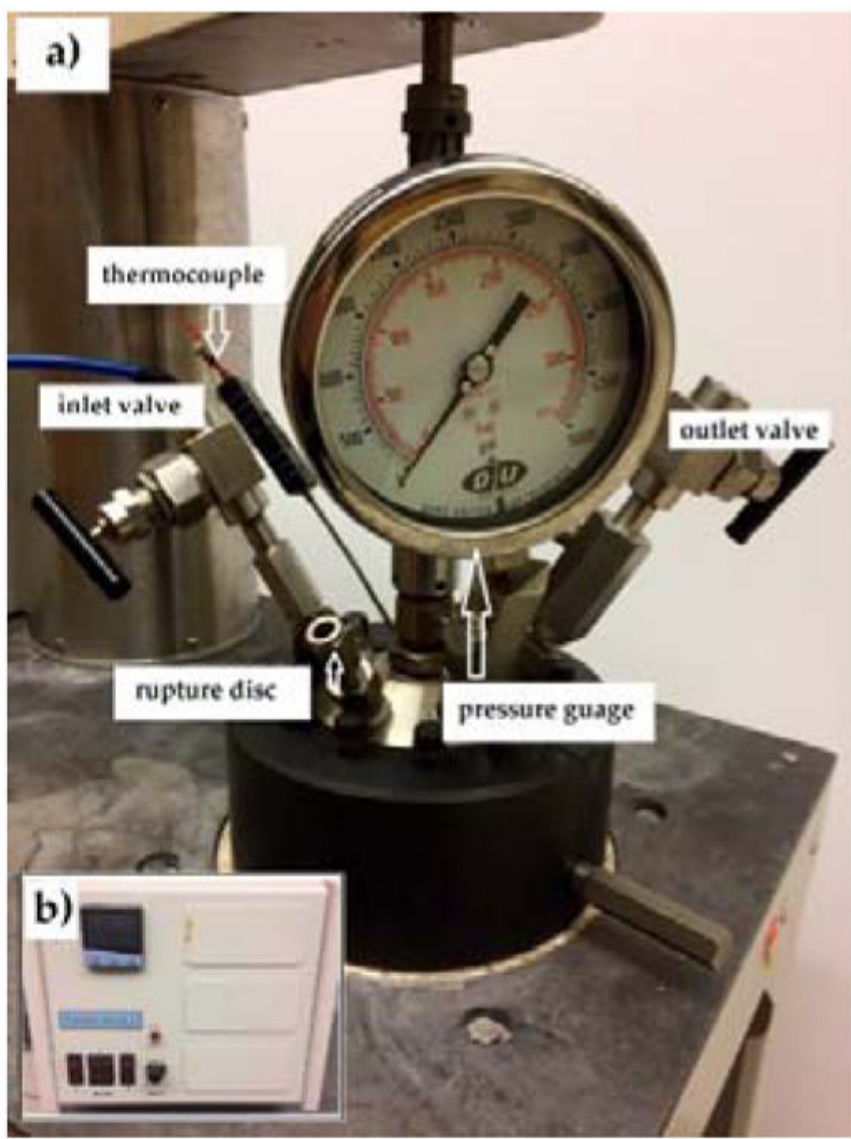

Figure 1.

a) $1 \mathrm{~L}$ Parr stirred reactor used for the reaction b) 4843 controller 


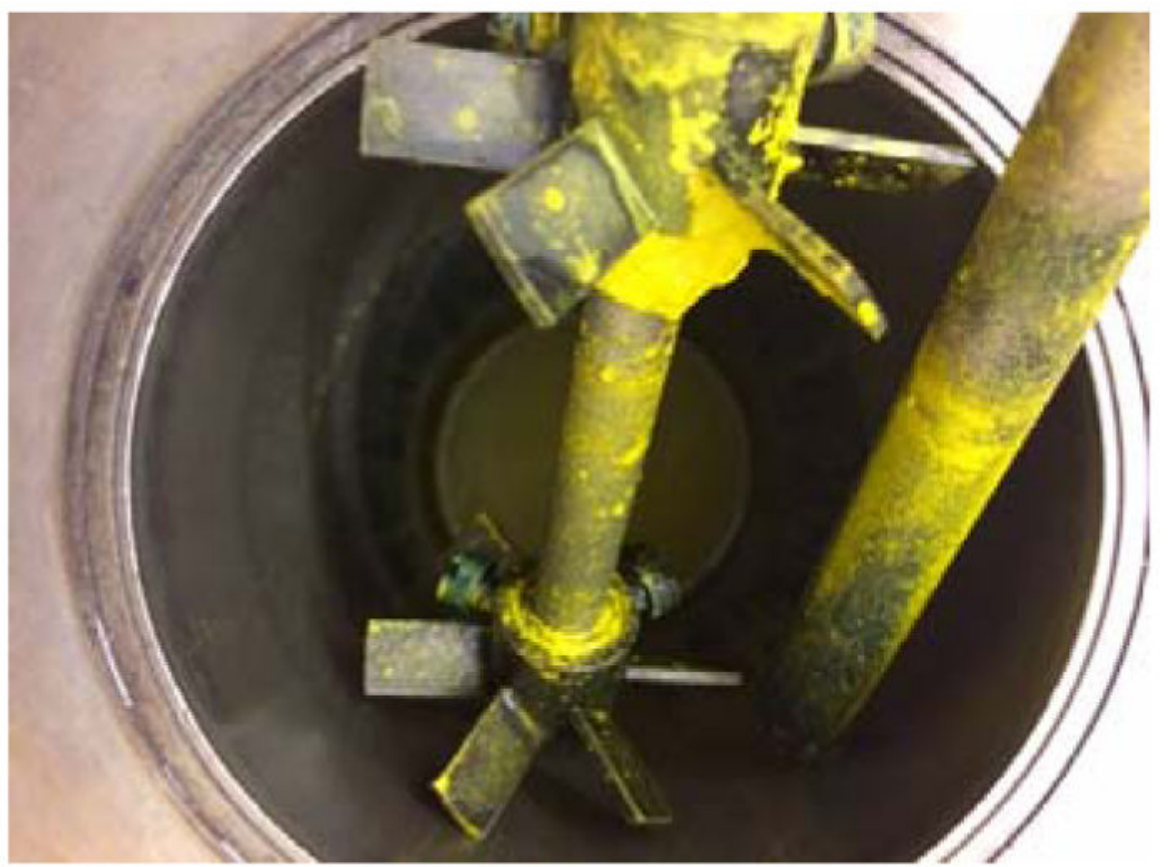

Figure 2.

An example of the insoluble yellow solid found on the internal components after a successful reaction 


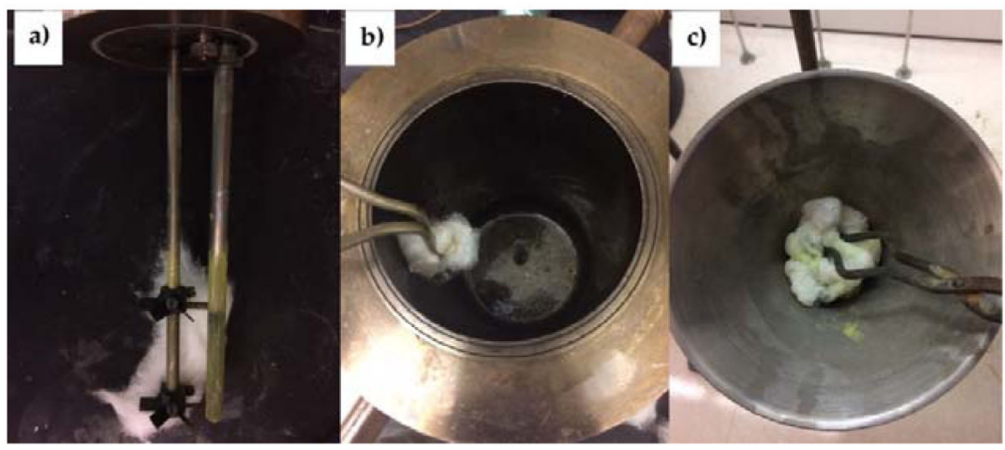

Figure 3.

a) yellow solid on stirring impellers b) mechanical scraping of yellow solid off the reactor walls c) extracting compound from cotton with tongs and solvent directly into funnel 


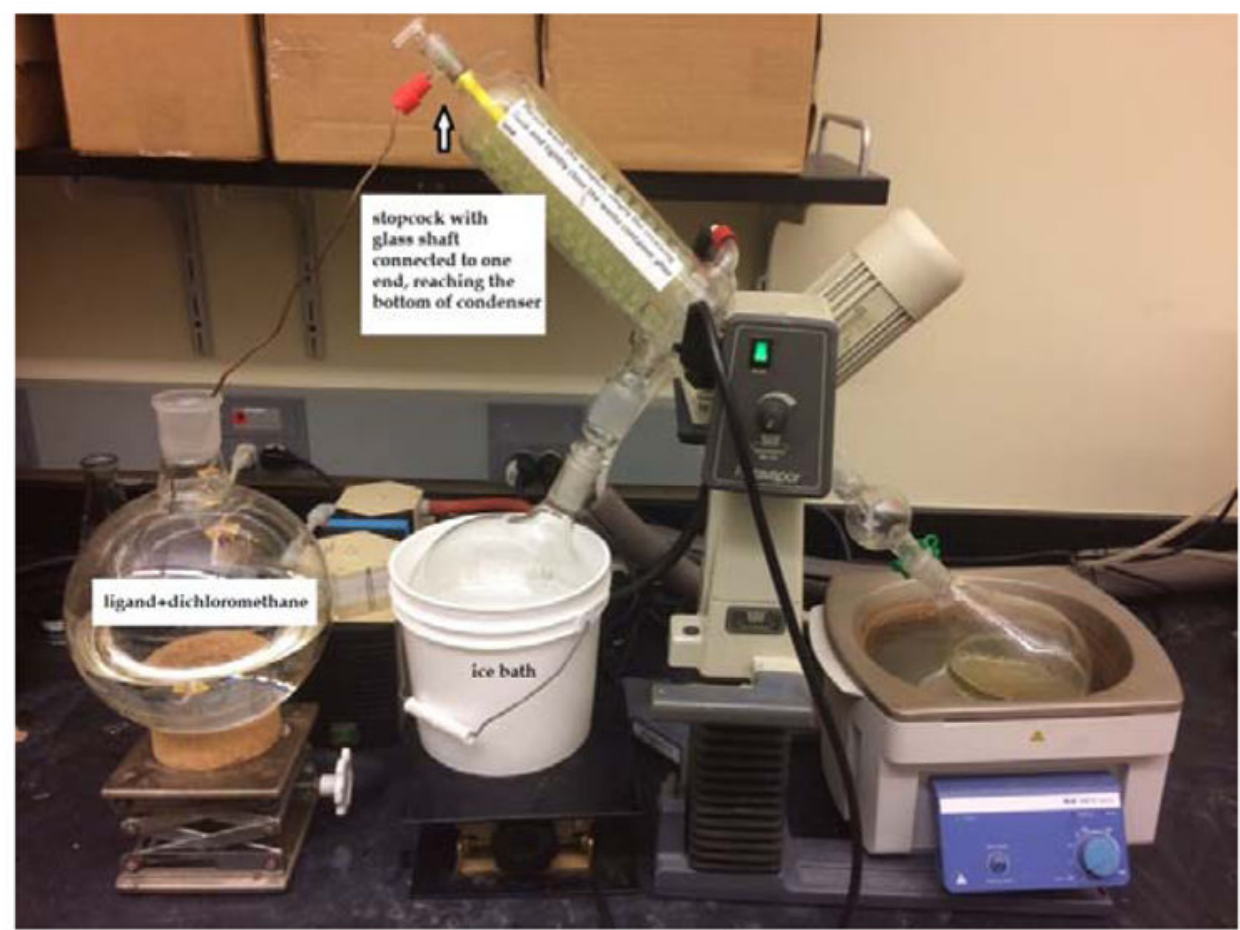

Figure 4.

Diagram of a continuous rotary evaporation setup 

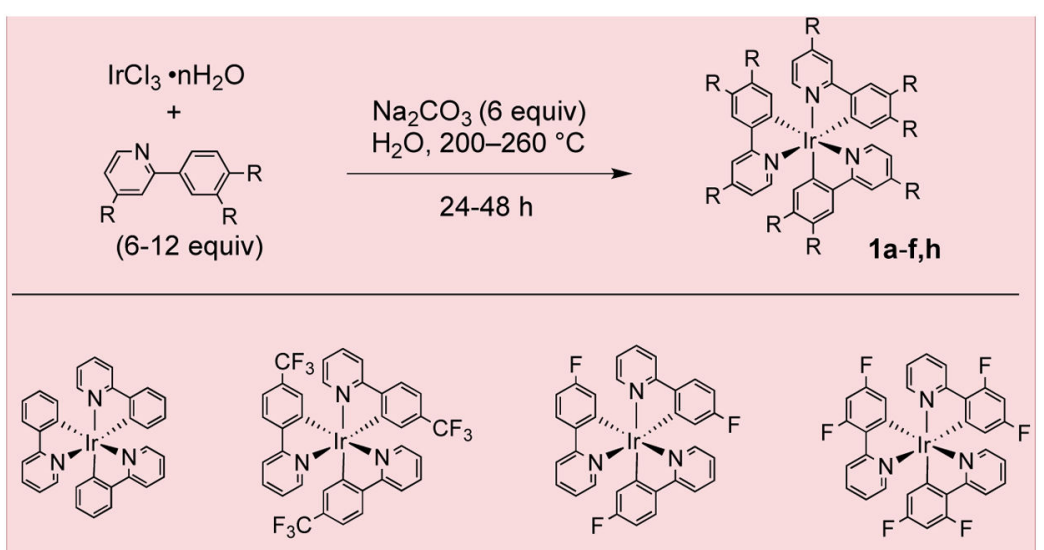

1a, $79 \%$

$1 b, 78 \%^{a}$

1c, $86 \%^{a}$

1d, $56 \%^{a}$

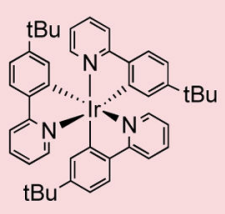

$1 e, 92 \%$

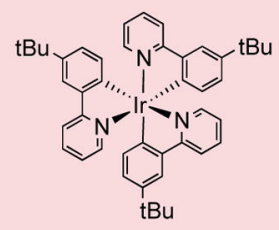

1f, $16 \%^{\text {a }}$

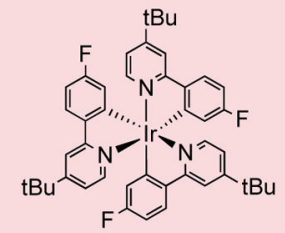

$1 \mathrm{~h}, 84 \%^{\mathrm{a}}$

Figure 5.

Synthesis of facial-homoleptic iridium complexes 
Table 1

Rf values of the photocatalyst and ligand

\begin{tabular}{|c|c|c|}
\hline Compound & $\mathbf{R}_{\mathbf{f}}: \mathbf{1 / 9}$ EtOAc/Hexanes & $\mathbf{R}_{\mathbf{f}}: \mathbf{1 / 1}$ DCM/Hexanes \\
\hline Fac-tris(2-phenylpyridinato) iridium(III) & 0.028 & 0.43 \\
\hline 2-Phenylpyridine & 0.31 & 0.19 \\
\hline
\end{tabular}

